\title{
Numerical Simulation of Impact of NOx Emissions of Foursquare Tangential Circle Boiler by Over Fire
}

\author{
Lei Du a , Yue Guo ${ }^{b}$, Long Jiang ${ }^{c}$, Qing Li ${ }^{d}$, Zhenning Zhao ${ }^{e}$ \\ North China Electric Power Research Institute Co Ltd. Beijing, 100045, China. \\ adulei426311@163.com, bhosa@163.com, ckaveykikiy@163.com, d13910680082@139.com, \\ ezhaozn@sina.com
}

\begin{abstract}
In this paper, the combustion and NOx emission characteristics of a $300 \mathrm{MW}$ tangential boiler are simulated, we obtain the flue gas velocity field in the hearth, component concentration distribution of temperature field and combustion products, and the speed, temperature, concentration of oxygen and NOx emissions compared with the test results in the waisting air distribution conditions, found the simulation values coincide well with the test value, to verify the rationality of the model. It will increase two over air vents in different location at $25 \mathrm{~m}, 28 \mathrm{~m}$ and $31 \mathrm{~m}$, the results show that, the location of $28 \mathrm{~m}$ is best height for over air.
\end{abstract}

Keywords: Numerical simulation; over fire; NOx emissions.

\section{Introduction}

Coal combustion process of nitrogen oxide (NOx) is one of the main pollutants of atmosphere pollution. The floorboard of the nitrogen oxide (NOx) is a variety of nitrogen oxides, including NO and $\mathrm{NO}_{2}, \mathrm{~N}_{2} \mathrm{O}$.NOx is nerve agents not only itself, but also in the atmosphere to form ozone $\left(\mathrm{O}^{3}\right)$ and acid rain, as a result of photochemical smog being great harm to human health by excessive ozone, NOx in the atmosphere to form acid rain, not only damage to human living environment, but also restricts the economic development. According to the calculation, the discharge into the atmosphere of nitrogen oxides in $7500 \times 10^{4} \mathrm{t}$, and most of nitrogen oxide is produced by burning process [1]. In our atmospheric pollutants produced by burning coal NOx accounted for about two-thirds of the total amount above, in view of the harm of nitrogen oxide, predominantly coal-fired power plant NOx emission reduction measures must be taken.

Numerical simulation of combustion process in the furnace is one of the important means for boiler design and renovation, to forecast the combustion characteristics, to control NOx emissions. In this paper, a power plant $300 \mathrm{MW}$ boiler are simulated to select the appropriate model, in different conditions, including compared with primary zone secondary waisting wind with the wind, uniform air distribution with three pagodas go down wind all the way of air distribution.

\section{Overview of boiler}

Type of boiler is HG-1025/18.2-WM10, the largest coal (MCR) being 1025t/h, Single furnace, Solid slag discharge, use four ball mill, silos in the coal pulverizing system, feeding hot air burner form for cocurrent, cut corners. The furnace is $12.808 \mathrm{~m}$ in width, $12.802 \mathrm{~m}$ in deepth, $55.25 \mathrm{~m}$ in height, and the main burner wall is hold burner band, the top of the boiler is equipped with many platen superheater, four corners of the Burner decorate have 5 primary air (PA), 12 secondary air (SA) and 2 tertiaryair (TA) nozzle, boiler structure size is shown in figure 1 below.

The element analysis and industry analysis of the boiler burning coal is shown in table 1. Low calorific value of coal Qar, net=21852 kJ/kg.

Table 1 Element and industrial analysis of the burning coal

\begin{tabular}{ccccccccc}
\hline \multicolumn{4}{c}{ Elemental analysis $(a r, \%)$} & \multicolumn{5}{c}{ Industry analysis $($ ar, \%) } \\
\hline$C$ & $H$ & $O^{*}$ & $N$ & $S$ & $M$ & $V$ & $A$ & $F c$ \\
58.49 & 2.55 & 2.24 & 1.14 & 0.4 & 11.86 & 6.968 & 23.32 & 57.852 \\
\hline
\end{tabular}



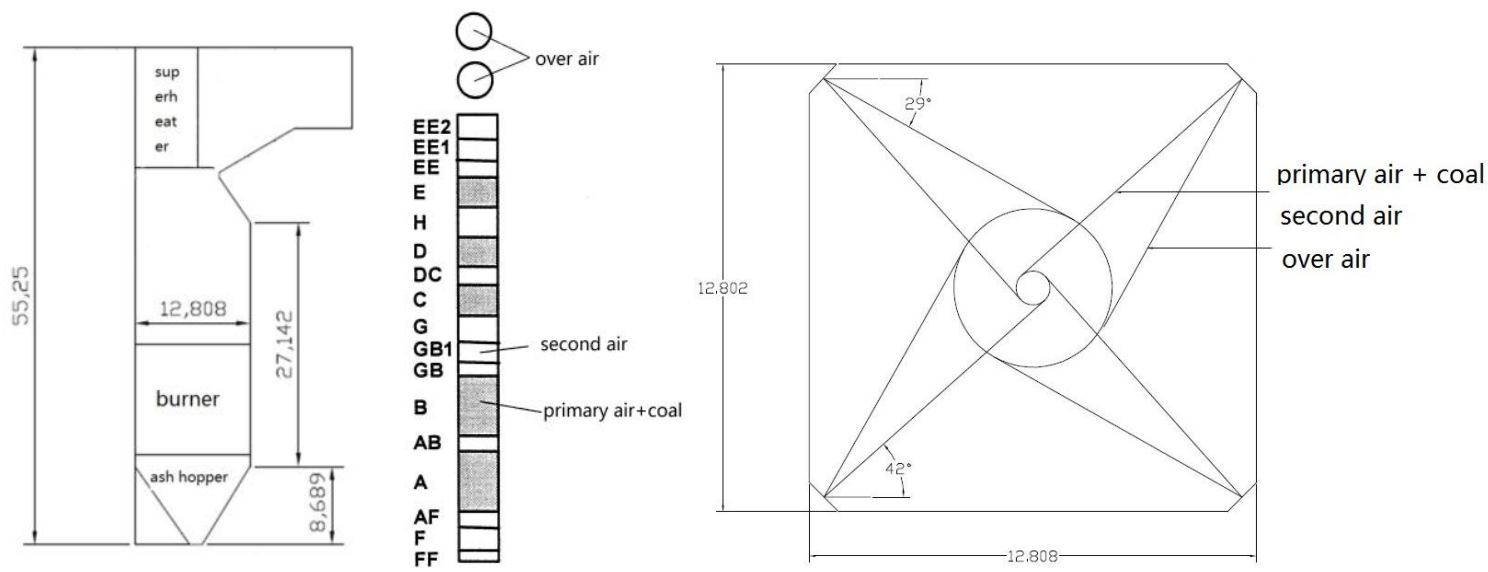

Figure 1 The schematic diagram of the furnace structure size and the combustion system structure

\section{Mathematical model and calculation conditions}

\subsection{Mathematical model}

We will use the Fluent 6.3.26 to carry out the research, the gas flow in a boiler furnace for three dimensional turbulent flow reaction, its average flow to be considered as steady flow, by using the standard k- $\varepsilon$ turbulence model. The mixed scores/probability density function model is used to simulate the gas phase turbulent combustion, the pulverized coal particle stochastic trajectory model is used to simulate motion; the double-equation parallel reaction model is used in the coal pyrolysis, coke combustion is controlled by power/diffusion reaction rate model, the method of P1 is used to the radiation heat transfer calculations.

NOx simulation consider mainly NO generation, involving thermal type NO and fuel type NO two kinds of mechanism. The thermal type NO is generated by $\mathrm{N}^{2}$ oxide in the air, is mainly affected by factors such as temperature, oxygen concentration, extended the Zeldovich mechanism of description to be used [2].For [O] and [OH] base, the partial balance method is calculated.

The fuel type NO is mainly generated by pyrolysis and oxidation reaction, as the main source of the NO. The fuel type NO is described by de Soete model, the fuel nitrogen is mainly distributed in the volatile and char, the volatile $\mathrm{N}$ is released of nitrogen in the form of $\mathrm{HCN}$ and $\mathrm{NH} 3$, and the coke's direct oxidation of nitrogen into the NO. Fuel nitrogen into the proportion of volatile nitrogen and coke nitrogen $\alpha$, volatile nitrogen into the proportion of $\mathrm{HCN}$ and $\mathrm{NH}_{3} \beta$, the percent conversion of coke nitrogen are important parameters to simulat accurattly NO generation. Typically, these parameter values are obtained by empirical methods, being difficult to adapt to the advanced combustion technology requirements for NO more accurate simulation. The predict nitrogen release process of advanced volatile chemical infiltration model is used [3], to preduice the fuel nitrogen in the proportion of volatile nitrogen and coke nitrogen, at the same time to obtain volatile nitrogen into the proportion of $\mathrm{HCN}$ and $\mathrm{NH}_{3}$. The coke nitrogen conversion is in commonly $40 \% \sim 60 \%$ [4], taking $60 \%$. The Beta - PDF model is used to calculate oxygen pulse generated NO by turbulent temperature.

\subsection{Calculation conditions}

The solving regional model is build according to the boiler furnace structure. The flow and combustion characteristic have symmetry in the hearth Because of the symmetry furnace structure. The mesh partition method is adopted. In burner exit area is grid refinement, to use of pave, in order to accurately simulate the flow characteristics of the area, as shown in figure 2 . 


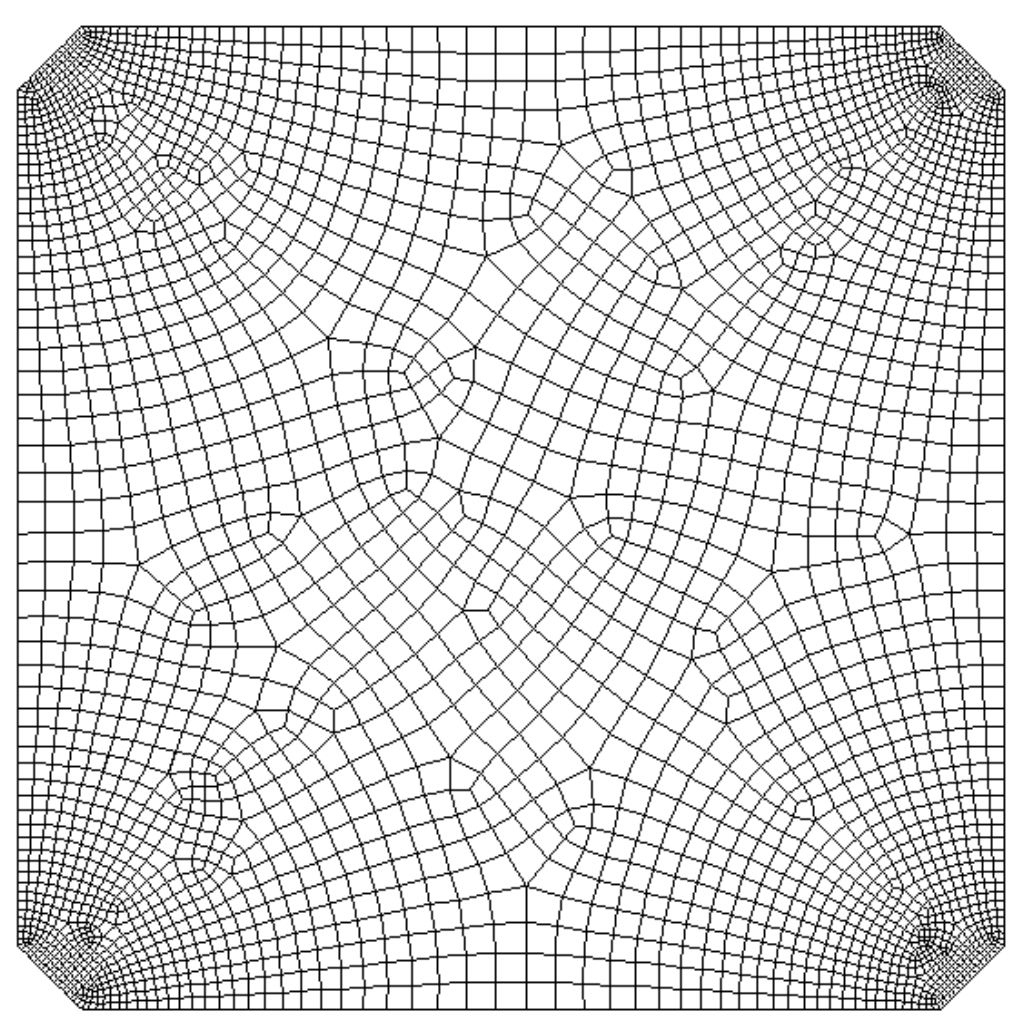

Figure $2 \mathrm{z}$ sectional view of the combustion zone

Burner and over air entrance are adopt velocity inlet boundary conditions, inlet velocity and temperature, are given by according to the operation parameters; Export use the pressure outlet boundary conditions; Furnace wall adopt sliding temperature boundary conditions. Pulverized coal particle diameter is according to the method of Rosin-Rammler, the primary air pulverized coal diameter is $56 \mu \mathrm{m}$, distribution index being 0.933 ; the over air average particle diameter is $13 \mu \mathrm{m}$, distribution index being 1.792. Refers to the former factor for char combustion kinetics parameters is $1.6 \mathrm{~g} /\left(\mathrm{m}^{2} \cdot \mathrm{s} \cdot \mathrm{Pa}\right)$, activation energy is $8.37 \times 104 \mathrm{~J} / \mathrm{mol}$.

Hot state test 1 , the air velocity of the nozzle under the condition of waisting air distribution are given according to the thermal state experiment measured values, primary air temperature $250^{\circ} \mathrm{C}$, second air temperature $360^{\circ} \mathrm{C}$, tertiary-air temperature $93^{\circ} \mathrm{C}$.tertiary-air velocity is $57.2 \mathrm{~m} / \mathrm{s}$ with powder amount $4.13 \mathrm{~kg} / \mathrm{s}$. The relevant data are shown as table 2 and table 3 .

Table 2 Waisting air distribution of secondary air inlet wind speed value

\begin{tabular}{ccccccccccccc}
\hline & $F F$ & $F$ & $A F$ & $A B$ & $G B$ & $G B_{2}$ & $G$ & $D C$ & $H$ & $E E$ & $E E_{1}$ & $E E_{2}$ \\
\hline $\begin{array}{c}\text { Waisting air } \\
\text { distribution value }\end{array}$ & 74 & 58 & 58 & 50.6 & 43.2 & 43.2 & 50.6 & 50.6 & 50.6 & 57.3 & 61.3 & 63.8 \\
\hline
\end{tabular}

Table 3 Each burner for coal distribution

\begin{tabular}{cccccc}
\hline & burner $A$ & burner $B$ & burner $C$ & burner $D$ & burner $E$ \\
\hline Coal feed quantity $(\mathrm{kg} / \mathrm{s})$ & 7.65 & 6.65 & 5.72 & 5.39 & 4.92 \\
\hline
\end{tabular}

Hot state test 2 ,in the chamber of a stove or furnace height to $25 \mathrm{~m}, 28 \mathrm{~m}$ and $31 \mathrm{~m}$ increase two burning air (SOFA) nozzle, speed of $50 \mathrm{~m} / \mathrm{s}$ air, temperature $360{ }^{\circ} \mathrm{C}$, the boundary conditions of primary air and secondary air and tertiary air are the same as the test 1.

Iteration calculation, SIMPLE algorithm to solve the discrete equations of pressure and velocity coupling, using line by line and low relaxation factor iteration method is used to solve the equation, the discrete method adopts first-order windward format. The convergence criteria for: Energy, radiation heat transfer, $\mathrm{NO}, \mathrm{HCN}$ and $\mathrm{NH}^{3}$ calculating residual error are less than $1 \times 10^{-6}$, the rest of the calculated residual error is less than $1 \times 10^{-3}$. 


\section{The results and analysis}

\subsection{Thermal test 1}

The velocity and temperature of the burner a center section of the waisting air distribution conditions is shown in figure 3 . The figure is visible, the tangential velocity field and temperature field of the tangential line is better.

The velocity, temperature and nitrogen oxides under waisting furnace center section are shown in figure 4 below. The figure show that the burner has formed a ring of low velocity area, mostly gathered at the chamber of a stove or furnace coal particles due to the lateral, the low speed region is good for increasing the combustion efficiency of the boiler running; In export position on both sides of the burner A is high temperature area, and extending down the bottom, it contributes to the stability of the flame in the hearth; Nitrogen concentration are in good agreement with the temperature field distribution.

Due to the excess air coefficient of the burner area being lesser, pulverized coal combustion generated NO being large reduction, NO concentration is low. Cold ash hopper area of oxygen concentration is higher, the generated NO is difficult to restore, so the concentration of NO is higher than the burner area. But due to the large number of into the over air, above the burner area, incomplete coal tar, and lead to NO generation, NO concentration increased. Near the platen superheater, because the burning coal tar reduction, NO concentration will be reduced. The NO molar concentration of exit is $478 \mathrm{ppm}$.
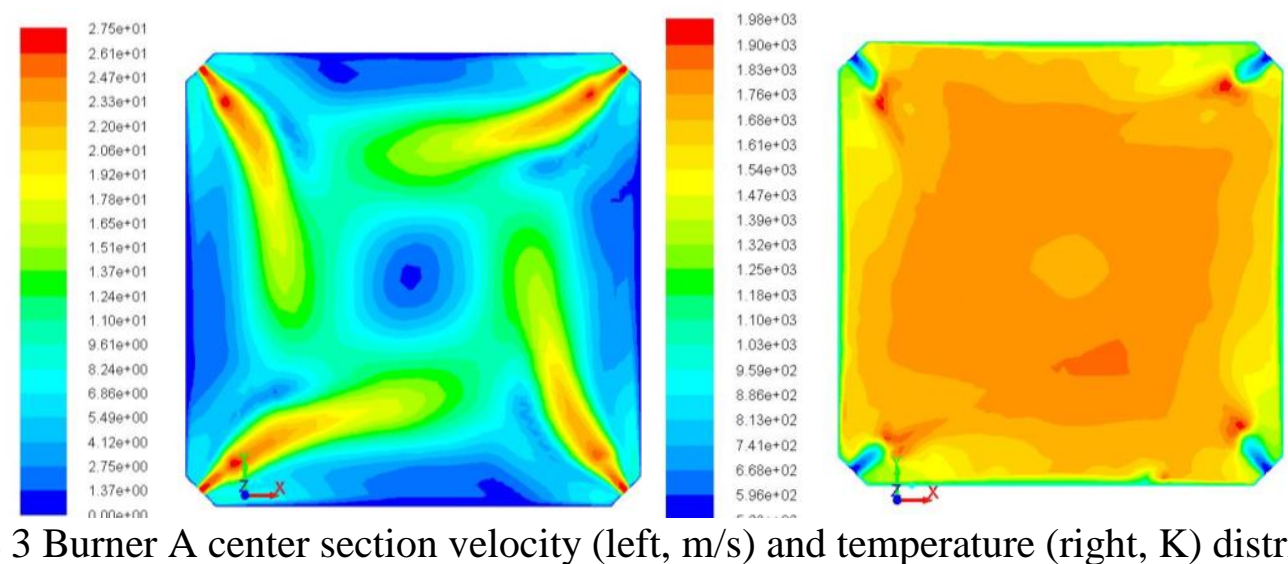

Figure 3 Burner A center section velocity (left, $\mathrm{m} / \mathrm{s}$ ) and temperature (right, K) distribution
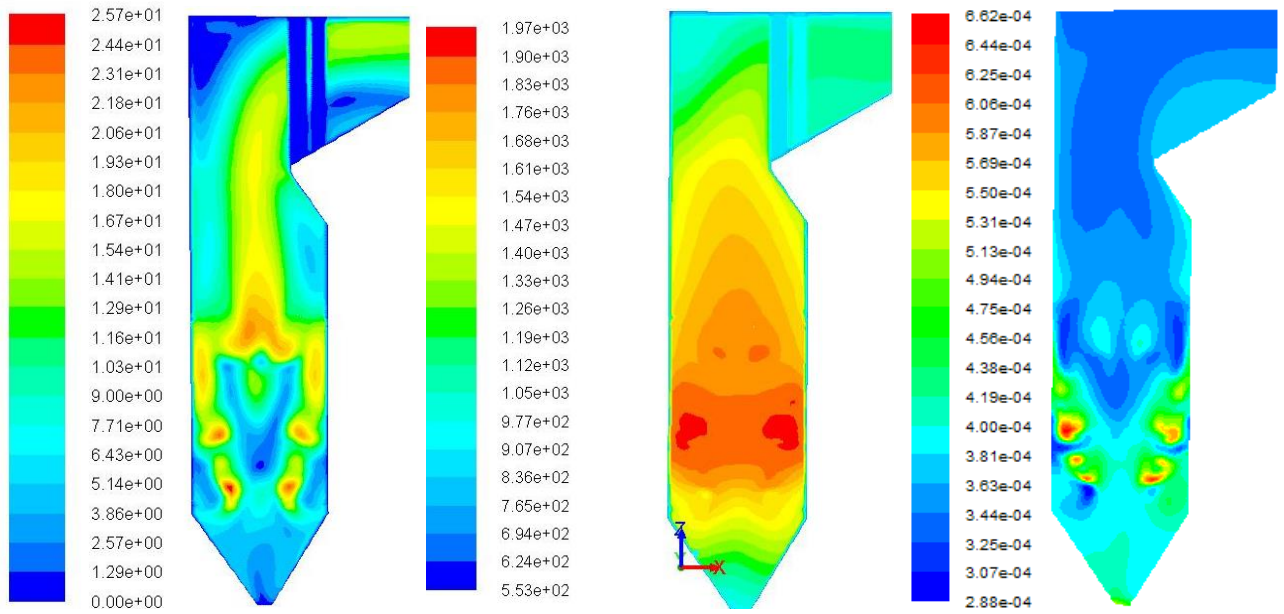

Figure 4 furnace center section speed $(\mathrm{m} / \mathrm{s}$, left), temperature (K, middle) and nitric oxide concentration distribution (right)

\subsection{Thermal test 2}

Figure 5 show that the fly ash carbon content, burnout rate and NO emissions $\left(\varphi\left(O_{2}\right)=6 \%\right)$ of exit in condition of different position of over air. 


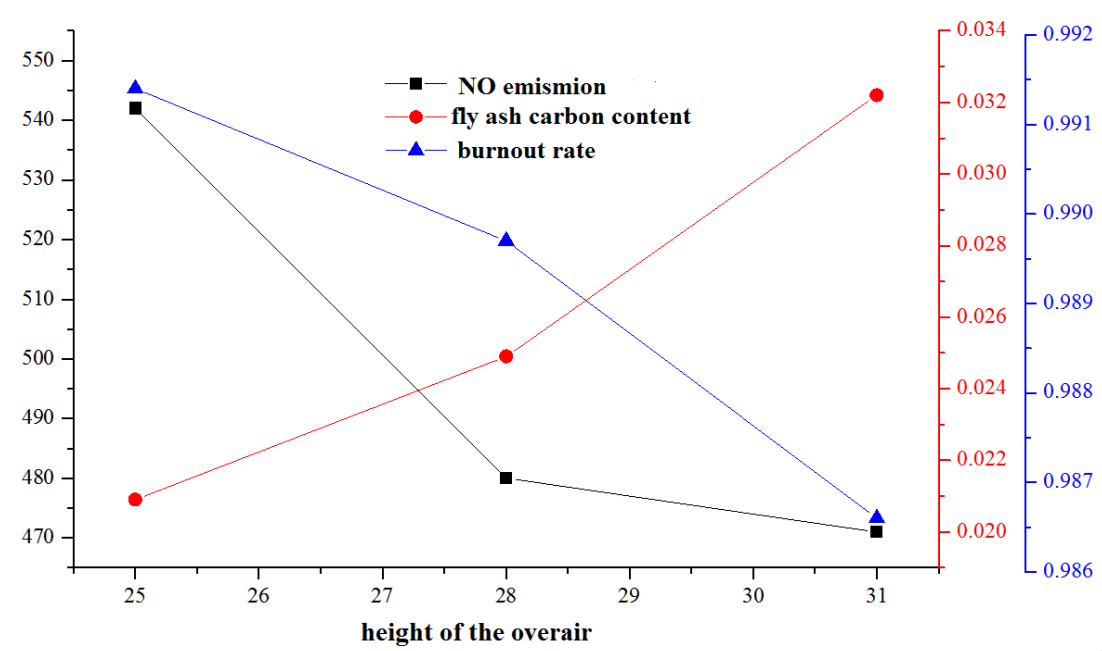

Figure 5 The fly ash carbon content, burnout rate and NO emissions of exit in condition of different position of over air

The fly ash carbon content increase with over air decorate the rise of the height. When over air position increase from $25 \mathrm{~m}$ to $28 \mathrm{~m}$, the fly ash carbon content increases slightly, and when over air position from $28 \mathrm{~m}$ up to $31 \mathrm{~m}$, almost linear increasing. And burning rate decreases with the rise of the height of over air. The height of the over air vents can lead to significantly lower combustion efficiency, excess air coefficient of the burner area is reduced, the incomplete combustion of coal particles increased, delay the pulverized coal burning, led to the rise of fly ash carbon content. With the over air rising, although there are a lot of air in the upper burner burning enters the furnace, but because of less burning time and the late hybrid not fully, the burning efficiency is still lower.

$\mathrm{NO}$ emissions increases with over air decorate the rise of the height, when over air arrangement under $28 \mathrm{~m}$, NO reduce emissions fast. This is because the burner area excess air coefficient decreases, and increased the degree of the incomplete combustion of the pulverized coal, combustion temperature decreases, the thermal type NO production is reduced, and the generated NO will be restored by over air to join in the upper furnace, so NO emissions is reduced.

The analysis shows that,when the over air is arrangement in $28 \mathrm{~m}$, fly ash carbon content is low, $\mathrm{NO}$ emissions is less than $500 \mathrm{mg} / \mathrm{m}^{3}\left(\varphi\left(\mathrm{O}_{2}\right)=6 \%\right)$, the location of $28 \mathrm{~m}$ is the best height for over air.

\section{Conclusion}

(1) The nitrogen oxides of the exit is lower in the condition of waisting air distribution, can be effectively reduced by over air.

(2) The fly ash carbon content increases with the rise of the height of over air, the burnout rate decreases with the rise of the height of over air, NO emissions increases the rise of the height of over air. When the over air is arrangement in $28 \mathrm{~m}$, the fly ash carbon content is low, the NO emissions is less than $500 \mathrm{mg} / \mathrm{m}^{3}\left(\varphi\left(O_{2}\right)=6 \%\right)$, it is the best height for over air.

\section{References}

[1] K. F. Cen, Q. Yao, Z. Y. Luo. Higher Combustion. Hangzhou: Zhejiang University Press, Hang Zhou, 2002.

[2] S. C. Hill, L. D. Smoot, Modeling of nitrogen oxides formation and destruction in combustion systems, Progress in Energy and Combustion Science. 26 (2000) 417-458.

[3] D. Genetti, T.H. Fletcher, Modeling nitrogen release during devolatilization on the basis of chemical structure of coal, Energy and Fuels. 13 (1999) 1082-1091.

[4] J. P. Spinti, D. W. Pershing, The fate of char-N at pulverized coal conditions, Combustion and Flame. 135 (2003) 299-313. 